Communication specialists have long been interested in analyzing messages. More recently, they have stressed the need for evaluative tools that account for situational expectations and constraints. Drawing from the literature on organizational and managerial effectiveness, we constructed an empirical model applicable to presentational communication. Over 100 communication professors evaluated the relevance of descriptors for six different types of business presentations: three oral and three written. Their judgments were used to create similarity scores, which were submitted to multidimensional scaling. A three-dimensional model emerged. This "competing values model" illustrates the dynamic interplay between the highly contrasting characteristics of four general types of presentational communication: relational, informational, instructional, and transformational. In conclusion, we discuss the benefits of the model and suggest its usefulness as an evaluative tool, particularly for the training of managers.

\title{
A Competing Values Framework for Analyzing Presentational Communication in Management Contexts
}

\author{
Robert E. Quinn \\ Herbert W. Hildebrandt \\ Priscilla S. Rogers \\ University of Michigan \\ Michael P. Thompson \\ Brigham Young University
}

Q ommunication is an ancient discipline which has evolved considerably. Throughout this evolutionary process, effectiveness has been a central concern. In the fifth century BC, for instance, Corax, one of the first teachers of human discourse, suggested the need for speakers to "produce an effect in listeners" (Hinks, 1940; Kennedy, 1959). Such a need filters through the ages in the voices of familiar sophists, rhetoricians, logicians, philosophers and textbook writers, as one pivotal question: How does one communicate effectively? In addressing this question, subsequent writers add, amend or critique the work of predecessors. Modern writers are no less hesitant to express dissatisfaction with the traditional approaches to presentational effectiveness. Smith (1968, p. 323), for example, calls for a "dynamic" model that views speech as a continuous stimulus stream with corresponding effects on the audience. Past models, he contends, are "static" and do not faithfully account for the communication processes they purport to describe, nor are they viable as generators of new communication research. Monge (1973) suggests that theory construction in the future should "focus on a new set of variables and employ a new set of analytic techniques" (p. 16). 
Growing criticism is also extended to speaking and writing "rules" that are a part of pedagogical texts. There is a recognition that formulaic, prescriptive approaches alone are insufficient. Halpern (1988) characterizes current pedagogy as "folklore and textbook incantations about what business and technical communications ought to be." Hagge (1989) believes pedagogy "ignores the real complexities of how writers actually get texts to cohere in the real world." Similarly, Huckin and Hutz (1987) conclude that the rules of the plain English movement lack a solid empirical base of support because they fail to depict how language is actually used.

Recent field research supports these views. Brown and Herndl (1986) discovered that managers deliberately employed superfluous nominalizations and narrative, structures understood as "verbose" and "muddy" and which these managers could have eliminated. Similarly, Rogers (1989) found that automotive field managers persisted in using narrative for their reports despite the company's declared preference for an inductive problemrecommendation format. These and other findings suggest the inadequacy of writing rules, forms and formulas that do not account for situational demands communicators face day-to-day. As Janis writes: "Anyone who is willing to make a comparison cannot fail to be impressed by the disparity between 'rules' that govern the style of business correspondence and the actual on-the-job performance in almost any large company" (1973, p. 81). The rules of rhetoric, Janis concludes, are unrealistic because they are not responsive to the context of communication.

As early as the fifties, social psychologists tried to replace the hunches of ancient rhetoricians with experimentally-grounded laws of behavior by identifying elements of messages that would trigger particular audience reactions. Hovland, Janis and Kelly (1953) actually tested various modes of message presentation and tried to measure changes in audience attitudes. Hovland and his colleagues were interested in many of the same questions that occupied earlier rhetoricians: Are messages on controversial topics more persuasive if their counter-arguments are included or omitted? Is an appeal to fear more effective than an appeal to some intrinsic rationality? Is it more effective to present the strongest arguments in a case first or last? In contrast to the ancients, Hovland and his contemporaries applied the scientific method to these questions. By analyzing audience reactions in a systematic way they attempted to make the art of rhetoric into a science in which audience reactions could be predicted. But, as Billig suggests, their dream was not realized.

Social psychologists working in the area of persuasion would freely admit that the bold vision of Hovland remains unfulfilled... .The clear principles whose discovery Hovland anticipated have not emerged. . . [and] the fixed 
rules of rhetoric have failed to materialize, despite the efforts of the old-style rhetoricians and their psychological descendents. $(1989$, pp. 69, 55)

What emerged from the work of Hovland and others was a bewildering collage of evidence and counter-evidence. Subsequently, as Fishbein and Ajzen (1981) conclude, much of the experimental work on communication "has been an accumulation of largely contradictory and inconsistent research findings with a few (if any) generalizable principles of effective communication" (p. 340).

Neither classical or renaissance rhetorical principles, nor contemporary social science research has provided unvarying rules for presentational effectiveness. At best we have only guidelines, expressed in the modern idiom of social psychology. As Billig (1989) notes, we are not much better at predicting and advising the functional orator today than we were 2500 years ago. However, Billig suggests, extensive experimentation on communication effectiveness has demonstrated the infinite complexity of rhetorical phenomena and the need for constant alertness to the possibility of exceptions.

We believe it is necessary to draw from both the traditionally-accepted precepts of the past and the experimental insights of the mid-twentieth century to develop theoretical and pedagogical approaches that ultimately help speakers and writers achieve results with their audiences. However, we also believe that past precepts and recent insights alone are insufficient. Today's message givers and message receivers operate in a diverse, complex, information-rich, rapidly changing, and often chaotic world. Consequently, theories of communication and tools for analyzing written and spoken presentations must be adaptable to a variety of contexts and must help communicators understand the complexities of their tasks and the multiplicity of their choices. In other words, contemporary notions of presentation must account for situational demands and present communicators with the possibility of exceptions to the traditionally established rules and norms. We believe the search for theoretical frameworks and analytical tools that address these needs is enriched by exploring studies on managerial effectiveness in the field of Organizational Behavior. Scholars in Organizational Behavior are engaged in a discussion very similar to ours. They, too, are debating the adequacy of traditional, rule-based approaches and exploring managerial adaptation to situational demands. As a result, organizational theorists have proposed a number of theoretical models, one of which we have found particularly useful for thinking about business presentations. After briefly reviewing this organizational model, we describe the methods used to build a similar model for presentational 
communication. We conclude by discussing the significance of this model for management communication.

\section{THE COMPETING VALUES MODEL}

In the literature of Organizational Behavior, many attempts have been made to answer the question, "What is an effective organization?" Of particular interest to us is a study that resulted in an integrative model of organizational effectiveness called the "competing values model." We describe the model below.

In a series of studies, Quinn and Rohrbaugh (1983) had organizational theorists and researchers make judgments regarding the similarity or dissimilarity between pairs of organizational descriptors. Multidimensional scaling was used to analyze the data. Results of the analyses suggested that organizational theorists and researchers shared an implicit theoretical framework, or cognitive map, for describing organizations. This framework became the basis for the competing values model illustrated in Figure 1.

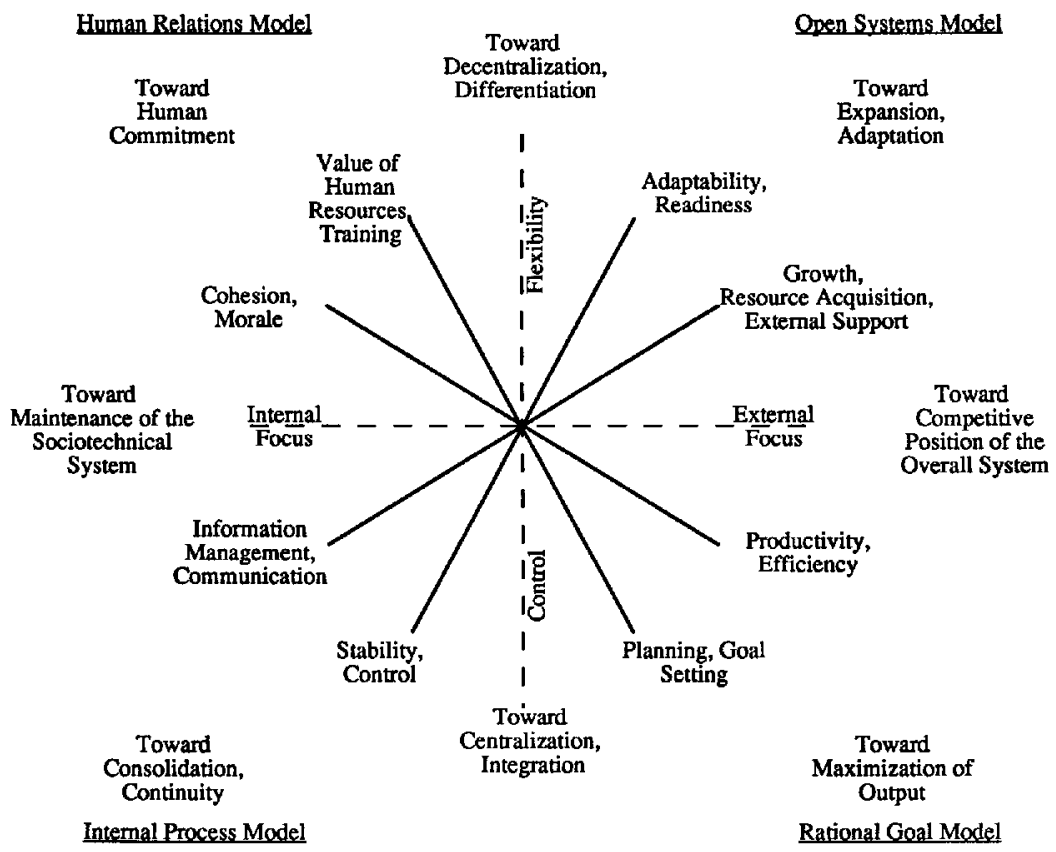

Figure 1. A competing values model of organizational effectiveness. From Beyond Rational Management: Mastering the Paradoxes and Competing Demands of High Performance (Quinn, 1988, p. 50). 
The competing values model has two axes which define four quadrants. The vertical axis ranges from flexibility to control; the horizontal axis ranges from an internal to an external focus. Each quadrant of the framework represents one of the four major organizational theories. In the human relations quadrant one finds descriptors such as cohesion and morale, criteria suggesting the value of human resources and training. Horizontally contiguous to the human relations quadrant is the open systems quadrant including descriptors such as adaptability, readiness, growth, resource acquisition, and external support. The lower-right rational goal quadrant includes descriptors such as planning, goal setting, productivity and efficiency. Last, the lower-right internal process quadrant includes information management and communication, stability, and control.

As presented in the model, each quadrant has a polar opposite. For instance, the human relations quadrant, emphasizing flexibility and internal focus, stands in stark contrast to the rational goal quadrant, emphasizing control and external focus. The open systems quadrant, characterizing flexibility and external focus, runs counter to the internal process quadrant where control and internal focus are valued.

Parallels among the quadrants are also important. For example, the human relations and open systems quadrants share an emphasis on flexibility. In the same manner, the open systems and rational goal quadrants have an external focus which responds to outside change and production needs in a competitive market. Central to both the internal process and rational goal quadrants is the concept of control; whereas the internal process and human relations quadrants share a concern for the human and technical systems inside the organization.

Brought together in this fashion, the four quadrants form a model that illustrates the conflicts or competing values of organizational life. We want our organizations to be adaptable and flexible, but we also want them to be stable and controlled. We want growth, resource acquisition, and external support, but we also want tight information management and formal communication. We want an emphasis on the value of human resources, but we also want an emphasis on planning and goal setting. The competing values model portrays these oppositions as mutually existing in real systems. By implication, it suggests that these descriptors, and the values and assumptions they represent, are oppositions only in our minds-we tend to think that the four organizational approaches are very different from one another, and may sometimes even assume them to be mutually exclusive. 
Quinn (1988) and his colleagues used the competing values model to analyze organizational and managerial performance. They found a major advantage inherent in the model. It allows the observer of an organization or of a manager to assess the presence of perceptually contrasting characteristics. In a certain situation an effective manager may behave in a way that is both caring and demanding; or a manager may take a position that advocates both change and stability. The model suggests these seemingly contrasting approaches may occur simultaneously and, in this way, it contributes to our understanding of managerial and organizational complexities.

Using Quinn's work as a guide, our research develops a similar model for communication. For this study, we sought to build a competing values model applicable to oral and written presentations in managerial contexts (Rogers, 1988). Most discussions of communication competence are, as Monge, Backman, Dillard, and Eisenberg (1983) point out, based on broader models developed by social psychologists. These models of social skills are more applicable to interpersonal communication than to business presentations such as technical briefings, sales demonstrations or technical reports, which may be more goal oriented and situationally constrained than interpersonal communication (Monge, et al., 1983, p. 506). We hope the model proposed here will serve as the foundation for instruments that allow us to evaluate the effectiveness of presentations in a variety of management contexts.

\section{METHOD}

To construct a competing values model for presentational communication, we employed a process similar to the one Quinn and Rohrbaugh (1983) used to build their organizational model. Generally, this process involved the following: (a) originating a comprehensive list of descriptors, (b) designing and distributing a research instrument that would provide information on the relevance of and relationships between the descriptors, and (c) analyzing responses to the research instrument using several computer programs that categorized and placed the descriptors in a model.

\section{Originating a Comprehensive List of Presentational Descriptors}

We originated a list of descriptors through a series of developmental steps. First, we asked three communication professors to individually compile exhaustive lists of characteristics of effective presentations by consulting communication textbooks and files of evaluation forms. Once 
their initial lists were created, we asked these professors to match each characteristic with a highly contrasting characteristic. If, for example, they listed the characteristic "technically correct," they might list a contrasting characteristic such as "creative" or "insightful." None of these contrasting characteristics were to be phrased negatively. This process forced them to think more comprehensively than they might have otherwise. Subsequently, five professors independently categorized the characteristics or descriptors from these lists. Their resulting categorized lists of descriptors were highly comparable. Slight differences were discussed until consensus was reached. This resulted in a single list of descriptors.

Second, using this list of descriptors, we developed a research instrument that asked respondents to indicate the extent to which each of the descriptors reflected each type of presentation. Forty-five management communication students completed this instrument. In performing the analysis we took an "appropriateness data" approach (Hair, Anderson, \& Tatham, 1987), which allowed us to obtain similarity measures on the descriptors. In the final instrument, respondents were asked to indicate how frequently good instances of each of the six types of presentation are characterized by the descriptors using a seven-point scale. Respondents' rankings of the descriptors in relationship to the six types of presentations became cases for drawing pairwise correlations between the descriptors. For example, if two descriptors are both ranked low on two types of presentations, moderate on two others, and high on the remaining two, then there is a high correlation between the descriptors, and they are treated as closely related. The correlation matrix became the distance measures submitted to multidimensional scaling. The results were used to eliminate highly redundant items and to combine neighboring items. To double-check our results we repeated this process with a second group of 43 students. The 16 sets of descriptors seen in Table 1 resulted from this process. The comprehensive and systematic nature of this multistep listing-reviewing-revising process leads us to believe that the sets of descriptors fairly represent the characteristics experts use to analyze presentations.

\section{Designing and Distributing the Research Instrument}

We subsequently designed a research instrument consisting of the 16 sets of descriptors and the six types of presentations seen in Table 1. Since the purpose of the six presentation types used in the research instrument was to associate the sets of descriptors, the key property of the presentation types had to be diversity. They did not need to be 


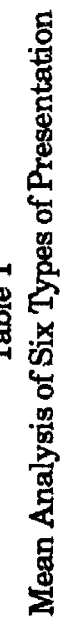

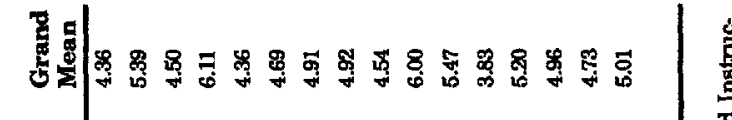

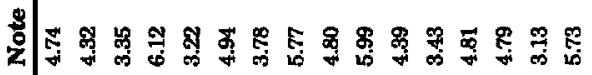

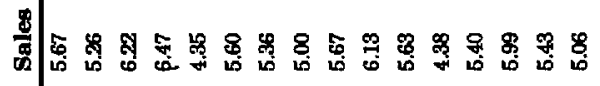

気

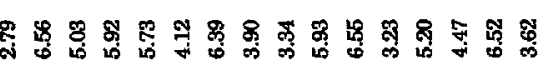

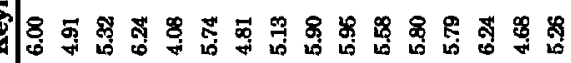

5

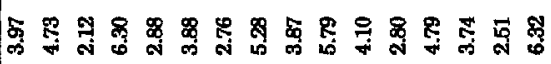

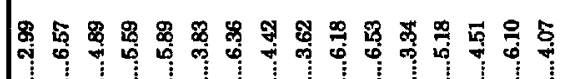

$+1$
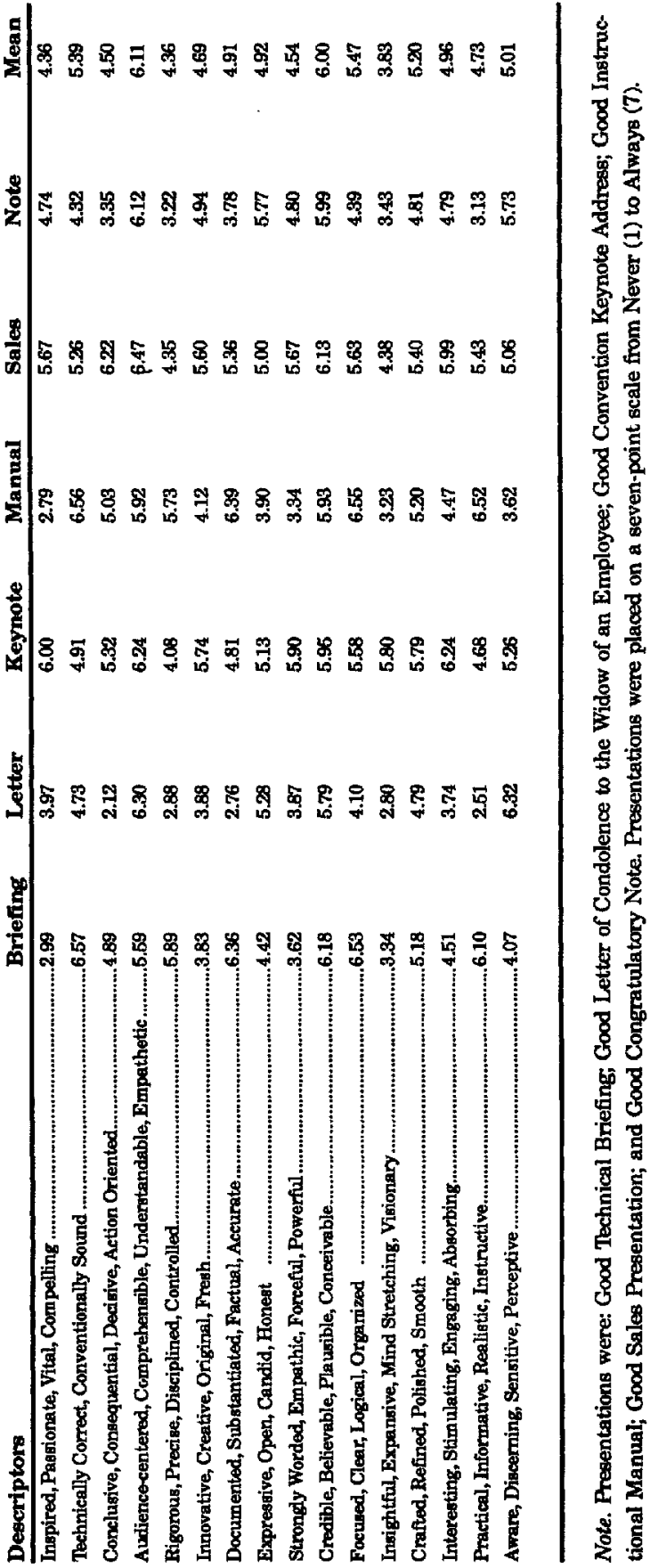
representative of all types of presentation. As can be seen in Table 1, the six presentation types we used are very diverse: technical briefing, letter of condolence to the widow of an employee, convention keynote address, instructional manual, sales presentation, and congratulatory note.

We mailed the research instrument to 150 communication professors, all members of communication journal boards and associations. The response rate was 70\%. Asking experts, who regularly evaluate presentations, to participate in our study was a logical first step. Testing the results using other groups remains for subsequent studies.

\section{Analyzing Responses to the Research Instrument}

The completed instruments were coded and analyzed using the same approach described earlier. All measures of similarity derived from the correlations between the sets of descriptors were analyzed using the SPSS multidimensional scaling program including the INDSCAL algorithm. INDSCAL, developed by Carrol and Chang (1970), assumes that respondents' judgments of similarity depend on the euclidian distances between stimuli in an underlying psychological space common to all participants. INDSCAL does not, however, assume that participants share common weightings for each dimension in this common space.

A summation of the grand means and the means for each of the six types of presentation can be seen in Table 1; grand means range from 3.83 to 6.11. All but one of the grand means are above four, the midpoint on the original scale. Only one grand mean falls below the midpoint, 3.83, hence, only one grand mean misses by less than .20 . This suggests that communication experts find all 16 sets of descriptors applicable to some extent.

Initial MDS results required a choice between a three-dimensional and a four-dimensional solution. The three-dimensional solution had a stress level of .189 and an $R$ squared of .603 . A view of the four-dimensional solution showed an improvement in both numbers (.142 and .628), but interpretability decayed badly. For this reason, the three-dimensional solution was selected (Kruskal \& Wish, 1978). It is shown in Figure 2.

\section{DISCUSSION}

Preliminary findings suggest that the participants in our study share an implicit framework for describing presentations. Furthermore, the analysis suggests the descriptors can be interpreted according to three dimensions, as seen in Figures 2 and 3 . The first dimension in Figure 3 


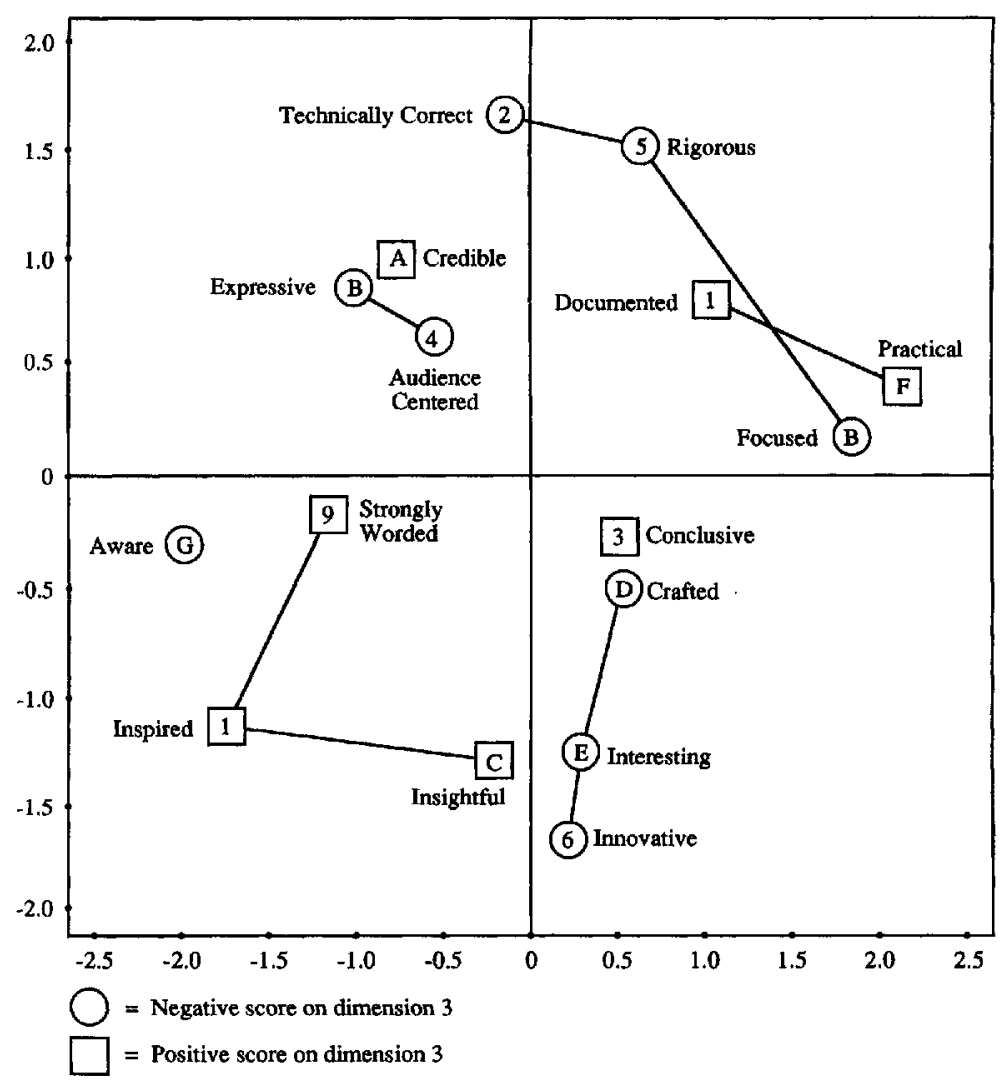

Figure 2. A multidimensional model of 16 effectiveness criteria.

is the equivalent of the horizontal axis in Figure 2. At one end of this first dimension are descriptors such as practical, informative, realistic, instructive, focused, clear, logical, and organized. At the other end are descriptors such as aware, discerning, sensitive, perceptive, inspired, passionate, vital and compelling. We have labeled this dimension "instrumental logic" at one end (which suggests focus and logical organization) and "relational awareness" at the other end (which suggests the expression of feeling).

The second dimension in Figure 3 is the equivalent of the vertical axis in Figure 2. At one end are descriptors such as technically correct, conventionally sound, rigorous, precise, disciplined and controlled. At the other end are descriptors such as innovative, creative, original, fresh, interesting, stimulating, engaging and absorbing. This dimension is 


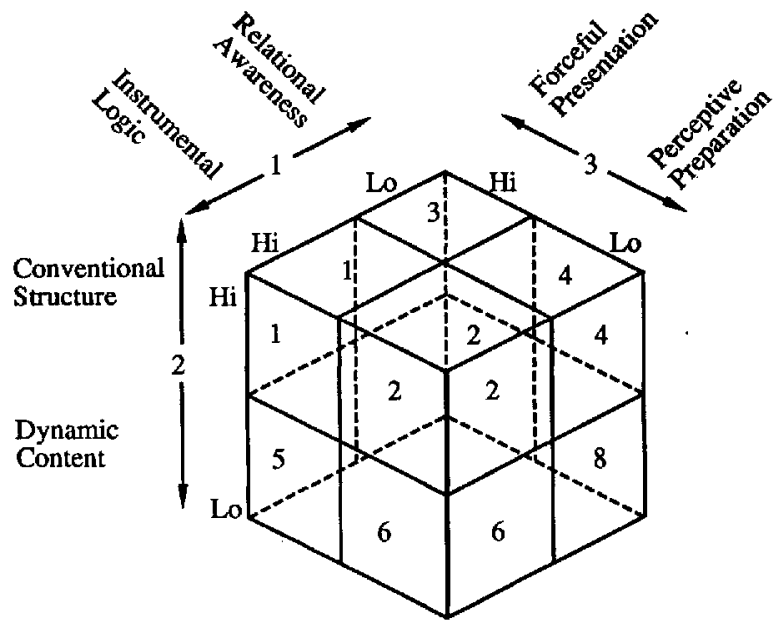

C

$\mathbf{E}$

$\mathbf{L}$

S DIMENSIONS

CRITERIA

$1 \quad 2 \quad 3$

1. Hi Hi Hi - Documented, Substantial, Factual Accurate

- Practical, Informative, Realistic, Instructive

2. Hi Hi Lo - Focused, Clear, Logical, Otganized

- Rigorous, Precise, Disciplined, Controlled

- Technically correct, Conventionally sound

3. $\mathrm{Hi} \mathrm{Lo} \mathrm{Hi}$ - Credible, Believable, Plausible, Conceivable

4. Hi Lo Lo - Audience centered, Comprehensible, Understandable, Empathetic

- Expressive, Open, Candid, Honest

5. Lo Hi Hi - Conclusive, Consequential, Decisive, Action oriented

6. Lo Hi Lo - Crafted, Refined, Polished, Smooth

- Interesting, Stimulating, Engaging, Absorbing

- Innovative, Creative, Original, Fresh

7. Lo Lo Hi - Strongly worded, Emphatic, Forceful, Powerful

- Insightful, Expansive, Mind stretching, Visionary

- Inspired, Passionate, Vital, Compelling

Figure 3. A simplified version of the three dimensional model.

labeled "conventional structure" at one end (which suggests following traditional rules), and "dynamic content" at the other end (which suggests innovative material). The third dimension in Figure 3 is repre- 
sented by the boxes and circles in Figure 2. At one end are descriptors such as documented, practical, credible, conclusive, strongly worded, insightful and inspired. At the other end are descriptors such as focused, rigorous, technically correct, audience centered, expressive, crafted, interesting, innovative and aware. The first we have labeled "forceful presentation" and the second "perceptive preparation."

\section{Four General Orientations}

The analysis and labeling of descriptors resulted in the competing values model of presentational communication seen in Figure 4. The first two dimensions in this model create a four quadrant space, which, in turn, suggests four different orientations toward managerial presentation. The lower left quadrant represents presentations high on conventional structure and instrumental logic. Therefore, descriptors including rigorous, precise, disciplined, controlled, focused, clear, logical and organized occur in this quadrant. We call this quadrant "informational communication" and suggest that it represents presentations that focus on providing facts.

The upper right quadrant represents presentations high on relational awareness and dynamic content. Here are descriptors including strongly worded, emphatic, forceful, powerful, insightful, expansive, mindstretching and visionary. In contrast to informational presentations that dispense facts, we call this quadrant "transformational communication" and suggest it represents presentations that focus on stimulating change. Here are the images and ideas of the charismatic presenter who creates new visions and paradigms in the minds of an audience. This communicator primarily aims to "transform" message receivers or stimulate change.

The lower right quadrant represents presentations high on instrumental logic and dynamic content. Here the descriptors are conclusive, consequential, decisive, action oriented, interesting, stimulating, engaging and absorbing. These descriptors suggest the quadrant be called "instructional" or "persuasive communication." Such presentations direct audiences toward specific actions.

In contrast is the upper left quadrant, which represents presentations high on conventional structure and relational awareness. Here the descriptors are credible, believable, plausible, conceivable, expressive, open, candid and honest. As opposed to instructional communication, which directs action, this quadrant is called "relational communication." The kind of presentations represented by this upper left quadrant focus on building trust and establishing rapport between people. 

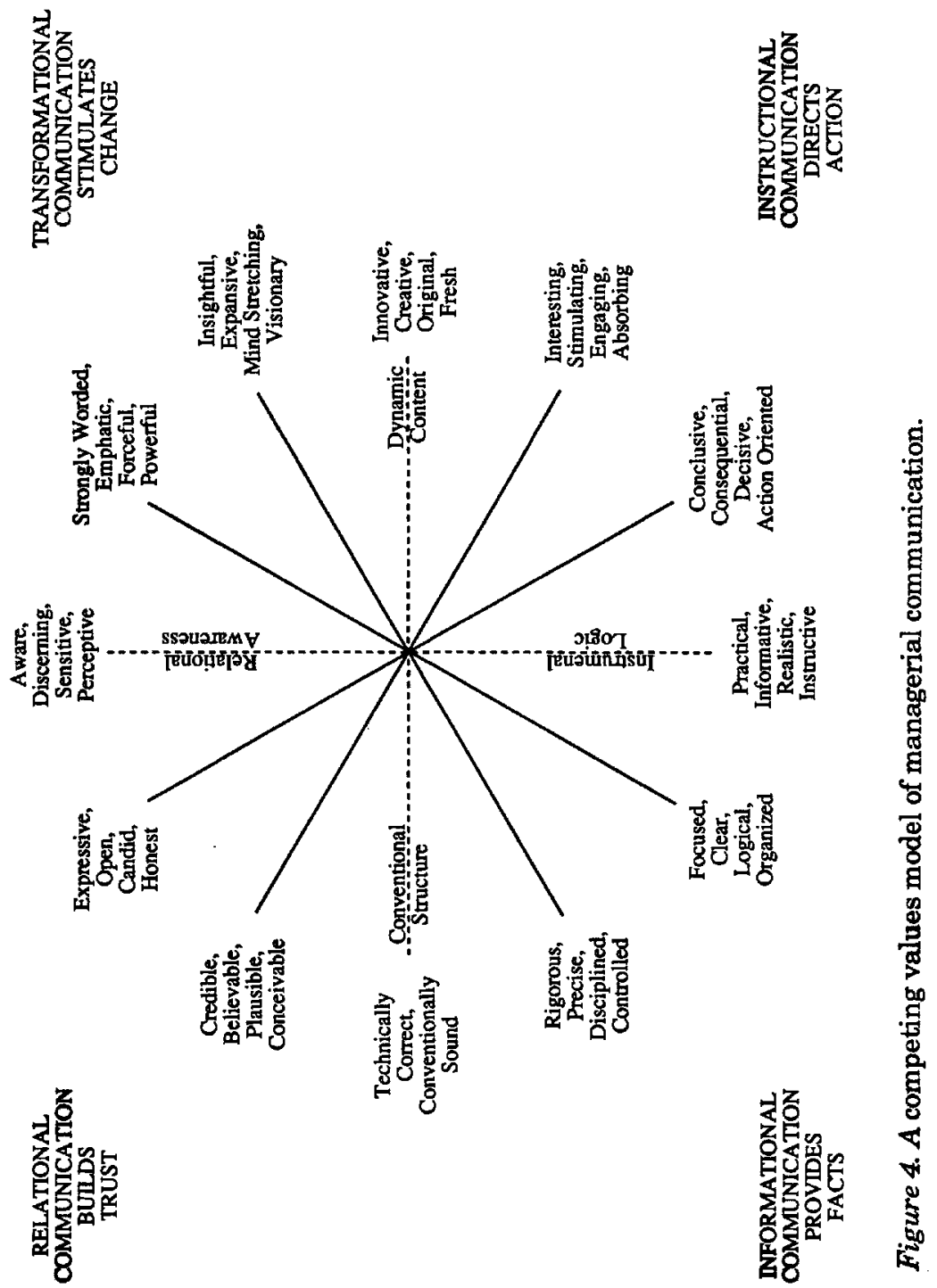


\section{ADVANTAGES OF THE MODEL}

The result of the preceding analysis is a competing values model for presentational communication. We believe this model articulates a set of perceptual relationships, which, in turn, have some important advantages for helping us analyze written and spoken presentations.

First, the model suggests that there are alternative approaches to viewing messages. As suggested earlier, the four quadrants in Figure 4 might be considered general orientations. Quinn's (1988) study of managerial leadership suggests that these are not emotionally neutral orientations, however. He found strong preferences among managers for leadership styles typified by certain quadrants. Similarly, it might also be expected that individuals will be biased toward certain styles of presentation; that is, some individuals may believe some orientations are inherently more important for effective presentations than others. Such assertions may arise from the success individuals experience with certain orientations or in particular contexts. It may further be argued that even textbooks may support some orientations over others. For example, the pedagogical literature on management communication (as on most topics in management) tends to display a strong orientation towards the two bottom quadrants. Going a step further, we suggest that not only individuals and texts may be biased, but even groups and cultures may be predisposed in a certain way. The two top quadrants, for example, may receive far less attention in organizations in the United States.

Second, the model suggests the paradoxical nature of effective presentations. That is, an effective presentation may include some ingredients from all four quadrants. Thus, a message characterized by one criterion in one quadrant without any trace of its opposite criterion in another quadrant, may be ineffective. A presentation, for example, that is high on all the descriptors associated with the informational communication quadrant and yet possesses none of the characteristics associated with the transformational communication quadrant may be so boring and monotonic as to receive virtually no consideration. Presentations of various types may possess more characteristics from one quadrant than any other; however, we assert that effective presentations must have some combination of characteristics from all the quadrants. In this way, the model suggests that effective spoken and written messages must achieve competing goals or possess characteristics that may, upon first thought, seem incompatible.

Figure 5 illustrates the above argument. In Figure 5 we use the model to profile the mean scores shown in Table 1 . These scores were obtained 


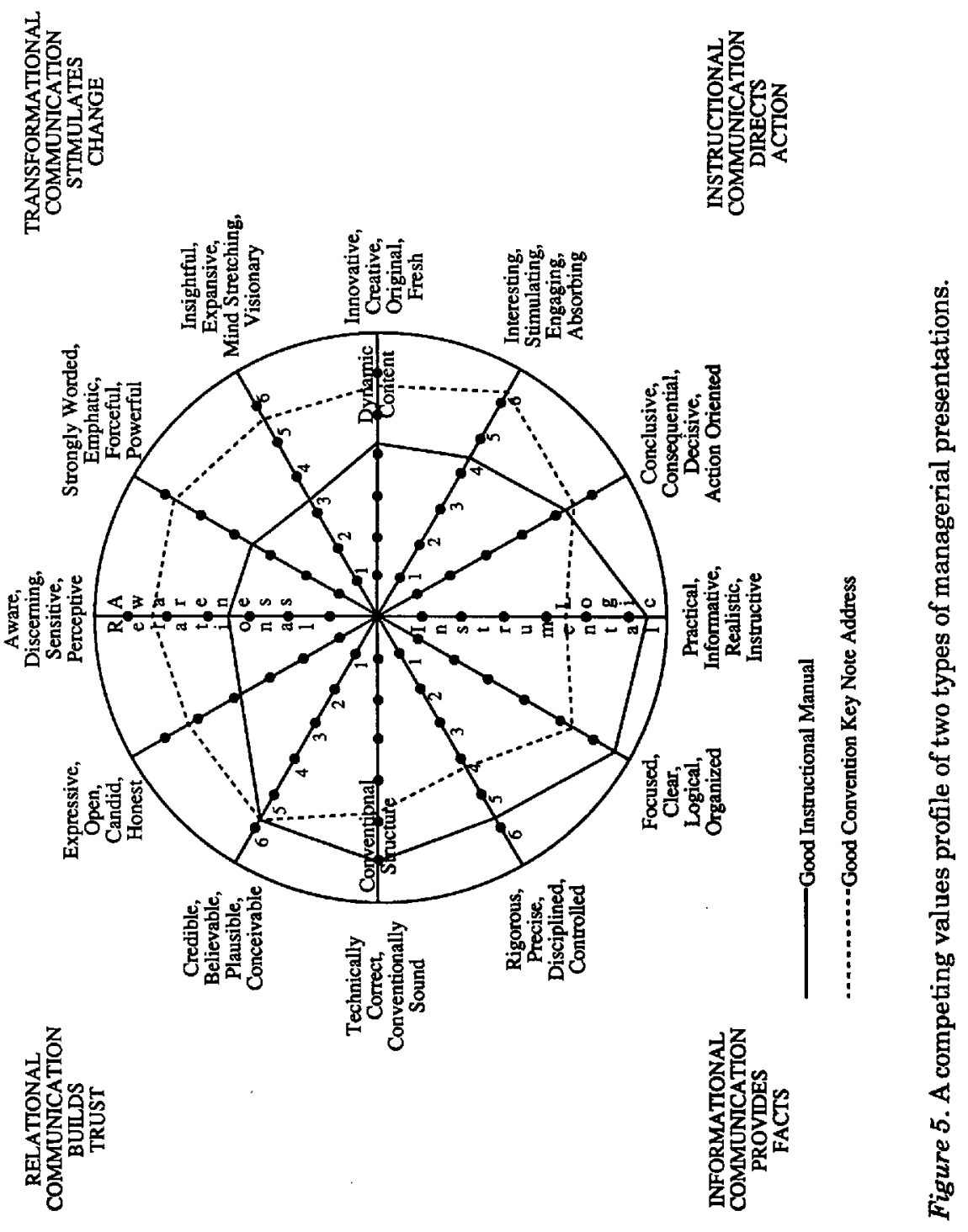


by analyzing respondents' rankings for two of the presentation types. A good keynote address, as represented in the collective judgment of our respondents, is indicated with a dotted line. Compare that profile with the solid line, which profiles our respondents' view of a good instructional manual. The two profiles contrast sharply, with the keynote address weighted towards the upper right and the instructional manual weighted toward the lower left. Notice, however, that the profile of the manual stays just below the midpoint for many of the descriptors in the upper right quadrant, while the keynote address is slightly above the midpoint on the descriptors in the lower left. This result suggests that, according to our respondents, each presentation type will manifest some contrasting characteristics. In this way, the profile keeps us from assuming away the presence of those characteristics not immediately associated with a given type of presentation.

Third, the model provides a scheme for empirically exploring the complexity and trade-offs involved in effective written and spoken presentations. Suppose, for example, that the 100 best instructional manuals were selected from all those published last year, and that each of the 100 best was then rated from 1 to 7 on each set of descriptors. Further suppose that the scores were then cluster analyzed so as to create subsets of manuals with similar characteristics and that each subset was then profiled on Figure 5. What would emerge from such an analysis? One subset of manuals might exactly fit the assumptions of our respondents as represented in the profile in Figure 5. Other manual profiles would, however, differ from that general expectation. These other profiles would show unexpected relationships among the descriptors. For example, one subset of manuals might have a profile similar to that of the convention keynote address. If this were so, an analysis of the manuals in that subset might modify our current thinking about writing instructional manuals. This argument would also hold for any other type of presentation. (For a parallel illustration, relating to management style, see Quinn, 1988).

As an aside, we note that the idea of certain characteristics associated with certain types of presentations raises the issue of context. The model does not itself map context. Our assumption is that both presenters and audience bring to the interchange their own constructs of context in any particular case. Audience assessment of message effectiveness stems from implicit views of contextual demands and audiences evaluate a presenter's success accordingly. However, our experiences with students and executives described below suggest the usefulness of the model as an evaluative tool in a variety of communication contexts. 
Fourth, the model can be used for applied as well as theoretical purposes. Student oral and written assignments can by analyzed with the model. For instance, the model has been used in the following manner in a graduate writing course: First, a student writer and other student readers score the student writer's document on each set of descriptors. Second, the means of these scores are used to create a competing values profile, in a manner similar to the results shown in Figure 5. Third, such an analysis is done for each class member, with all completed profiles coming to the instructor. Fourth, three results occur: (a) the students have individual profiles of themselves on at least one document; (b) the instructor has a profile of the entire class; and (c) the instructor can give feedback on specific areas to both the student and the class as a whole. Here then are interesting possibilities in linking communication analysis, feedback, and improvement efforts with the similarly structured management improvement framework outlined in Quinn, Faerman, Thompson and McGrath (1990). ${ }^{1}$

A similar feedback procedure may be applied to oral presentations. After a presentation, the student speaker and class members plot that presentation on the model. In other words, they create a competing values profile of the presentation. Immediately, student speakers have a visualization of their performance, and can begin thinking of ways to improve their next presentation.

We find that executives also respond positively to this kind of presentation analysis. With executives we collect, prior to training, individual competing values profiles of each participant's presentational communication abilities, which are completed by peers, subordinates, superiors, and the executives themselves. In other words, four profiles are created, permitting visual comparisons as to agreements and differences between the evaluators. Executives then meet with the communication trainer, who provides analysis and suggestions for change. Subsequent presentations allow additional analysis to determine whether progress occurs.

When reviewing the competing values profiles with the executives, we have discovered that the model lends itself well to discussing interpersonal communication skills. ${ }^{2}$ In fact, many of the peers, subordinates and superiors involved suggested that we build a model that identifies interpersonal variables. The presentational model offered here might also be applied to group communication.

We hope the competing values model proposed here is useful in studying oral and written presentations in a variety of managerial contexts. The model may help us understand what audiences expect from 
various presentations and how audience reactions compare with a presenter's intentions - we know from research that compares self assessments with assessments by others that communicators often evaluate their effectiveness very differently than do their peers, subordinates and superiors in the same organization (Sypher \& Sypher, 1984). Perhaps the model can help us determine more precisely how presenters' intentions and audiences' reactions differ.

In concluding, we note that the competing values framework suggested by our model is tentative and developmental. This study is an effort to conceptualize at a very general level. While we use data and systematic analyses that can be replicated, the data are ultimately based on the subjective judgments of communication specialists. Surely the descriptors in the model might be rearranged into numerous patterns. Additional descriptors might also be identified and different presentation types might be employed. Alternative analytic methods might also be used. All would modify the present findings. It should be remembered, however, that rather than finding some preexisting, empirical reality, we are here engaged in the process of creating meaning.

Ultimately, the competing values model offered here is a theoretical tool. We are empirically and systematically building a model that normally would be developed in the armchair of some scholar. Our efforts are exploratory and our expectations are modest. We see this as an initial model, one that starts a conversation, and leads to future improvements. Along the way, we hope it provides some useful insights into the analysis of written and spoken presentations.

\section{NOTES}

This research was supported by The University of Michigan School of Business Administration. We extend special thanks to Carol Mohr and Christi Bemister who prepared the final manuscript, figures, and table. A copy of the research instrument is available from the third author.

${ }^{1}$ Presentational success or failure is usually focused upon audience response. Granted, functionality is not all there is to assessing competence (Spitzberg, 1983, p. 327). We all want to apply other intrinsic criteria to communication assessment - such as tests of truth or candor, or the uprightness of the presentor's motives. But competence, as we define it, is primarily a function of goal attainment.

${ }^{2}$ We do not assume that the present model is applicable, without modification, to interpersonal communication. We did not, for example, use the management interview as one of our types of presentation, because it is, we believe, more representative of a "regulative situation" (O'Keefe \& McCornack, 
1987, p. 69). In that situation, the more interactional criteria of interpersonal communication models are more appropriate.

\section{REFERENCES}

Billig, M. (1989). Arguing and thinking:A rhetorical approach to social psychology. Cambridge: Cambridge University Press.

Brown, R.L., \& Herndl, C.C. (1986). An ethnographic study of corporate writing: Job status as reflected in written texts. In B. Couture (Ed.), Functional approaches to writing: Research perspectives (pp.11-28). Norwood, NJ: Ablex.

Carroll, J.D., \& Chang, J.F. (1970). Analysis of individual differences in multidimensional scaling via an $\mathrm{N}$-way generalization of Eckhart Young decomposition. Psychometrika, 35, 283-319.

Fishbein, M. \& Ajzen, I. (1981). Acceptance, yielding and impact: Cognitive processes in persuasion. In R.E. Petty et al. (Eds.). Cognitive responses in persuasion (pp.339-359). Hinsdale: Lawrence Erlbaum.

Hagge, J. (1989). The spurious paternity of business communication principles. The Journal of Business Communication, 26, 33-55.

Hair, J.F., Anderson, R.E., \& Tatham, R.C. (1987). Multivariate data analysis (2nd ed). New York: Macmillan.

Halpern, J.W. (1988). Getting in deep: Using qualitative research in business and technical communication. Journal of Business and Technical Communication, 2(2), 22-43.

Hinks, D.A.G. (1940). Tisias and Corax and the invention of rhetoric. Classical Quarterly, 34(1,2), 61-69.

Hovland, C.I., Janis, I.L., \& Kelly, H.H. (1953). Communication and persuasion. New Haven: Yale University Press.

Huckin, T.N., \& Hutz, L. (1987). Existential "there." (CDC Technical Report No. 36). Pittsburgh, PA: Carnegie Mellon University.

Janis, J.H. (1973). The writing behavior of businessmen. Journal of Communication, 15, 1965, 81-88.

Kennedy, G.A. (1959). The earliest rhetorical handbooks. American Journal of Philology, 80(2), 169-178.

Kruskal, J.B., \& Wish, M. (1978). Multidimensional scaling. Beverly Hills, CA: Sage.

Monge, P.R. (1973). Theory construction in the study of communication: The system paradigm. Journal of Communication, 23, 5-16.

Monge, P.R., Backman, S.G., Dillard, J.P., \& Eisenberg, E.M. (1983). Communicator competence in the workplace: Model testing and scale development. In M. Burgoon (Ed.), Communication Yearbook 5 ( pp. 505-528). New Brunswick, N.J.: Transaction. 
O'Keefe, B.J., \& McCornack, S A. (1987). Message design logic and message goal structure: Effects on perceptions of message quality in regulative communication situations. Human Communication Research, 14, 68-92.

Quinn, R.E. (1988). Beyond rational management: Mastering the paradoxes and competing demands of high performance. San Francisco: Jossey-Bass.

Quinn, R.E., Faerman, S.R., Thompson, M.P., \& McGrath, M.R. (1990). Becoming a master manager: A competency framework. New York: Wiley.

Quinn, R.E. \& Rohrbaugh, J. (1983). A spatial model of effectiveness criteria: Towards a competing values approach to organizational analysis. Management Science, 29(3), 363-377.

Rogers, P.S. (1988). Distinguishing public and presentational speaking. Management Communication Quarterly, 2, 102-115.

Rogers, P.S. (1989). Choice-based writing in managerial contexts: The case of the Dealer Contact Report. The Journal of Business Communication, 26, 197-216.

Smith, R.G. (1968). Public speaking models: Process and response. Southern Speech Journal, 33, 316-327.

Spitzberg, B.H. (1983). Communication competence as knowledge, skill and impression. Communication Education, 32, 323-329.

Sypher, B.D., \& Sypher, H.E. (1984). Seeing ourselves as others see us: Convergence and divergence in assessments of communication behavior. Communication Research, 11(7), 97-115. 